\title{
Cost Optimisation Based on Electro-Mechanical Equipment of Canal Based Low Head Small Hydropower Scheme
}

\author{
Singal S.K..$^{*}$, Saini R.P. ${ }^{2}$ and Raghuvanshi C.S. ${ }^{3}$ \\ ${ }^{I}$ SSO, AHEC, IIT, Roorkee-India; ${ }^{2}$ AHEC, IIT, Roorkee-India; ${ }^{3}$ WRDM, IIT, Roorkee-India
}

\begin{abstract}
Absract: In the present paper an attempt has been made to develop the correlations for the cost of different components of canal based small hydropower (SHP) schemes. The cost has been determined based on actual quantities of various items having prevailing rates. The developed correlations give the plant cost as the function of cost sensitive parameters for various layouts based on different type of turbines and generators. An attempt has also been made to evolve the optimum selection of layout based on installation cost, generation cost and benefit cost ratio at different load factors. It has been found that the power house layout having tubular turbine with propellor runner and induction genertor is optimum layout at high load factors i.e. 90 to $100 \%$, while, layout having bulb turbine with Kaplan runner is optimum at low load factor $(50 \%)$.
\end{abstract}

Keywords: Benefit-cost ratio, generation cost, installation cost, low head, optimization, small hydropower, electro-mechanical equipment.

\section{INTRODUCTION}

The economic environment in India has undergone rapid transition in a short span of time. Recognizing the crucial role of energy in propelling and sustaining the momentum of growth, Government of India has accorded high priority to this sector. The objective is to provide reliable, affordable and sustainable energy to all consumers. Hydropower is one of the most important natural resources of renewable energy. It is required to give more emphasis on development of renewable sources of energy and adoption of energy efficient and clean technologies to the extent possible. Hydropower represents non-consumptive, non-radioactive, and nonpolluting use of water resources towards inflation free energy development with mature technology and spectacular operational flexibility. Worldwide total hydropower capacity in operation is $807 \mathrm{GW}$ with annual generation of 3030 TWh/year. Presently, hydropower is contributing more than 50 percent of electricity supply in about 60 countries. Hydropower, large and small has been important source of energy in all European countries possessing water potentials [1].

India started with total installed capacity of $1362 \mathrm{MW}$ at 1500 sites and per capita consumption of $14 \mathrm{kWh}$ in 1947 when it got its independence. The hydropower capacity increased from 508 MW in 1947 to 20366 MW in 1994. In recent years, Indian economy has been growing at a rate exceeding $6.5 \%$ and expected to be maintained in coming years, thus demand for energy will increase accordingly. The present installed capacity of power generation in India is $127055 \mathrm{MW}$; out of which hydropower is $26 \%$, thermal is $66 \%$, renewable is $5 \%$ and nuclear is $3 \%$. The country is still short of power. The shortage is $7 \%$ on an average and $11.2 \%$

*Address correspondence to this author at the AHEC, IIT, Rorkee-India; Tel: +91 1332 285167; Fax: +91-1332 273517;

E-mail: sunilfah@iitr.ernet.in, sunilksingal@gmail.com at the time of peaking [2]. The current concern on the global environment has imposed a new restrain on the production of electricity and the emphasis is put on the development of environment friendly energies to promote the sustainable social development. It is in these circumstances, small hydropower is drawing more attention. The possibilities of small hydro schemes in the plains usually occur on the canal falls that would be existing in the irrigation canal system. Such schemes are also very much amenable for connection to nearby grid. The canal based schemes utilizes power potential available due to flowing water and head at canal falls. In the alignment of canal, it is required to provide falls to match the levels of canal with the surrounding natural ground levels.

There are 4445 identified potential SHP sites in different states of India with an aggregate capacity of 10835 MW. These sites are under different categories such as run of river, dam based and canal based schemes. There are about 1700 canal based sites having total capacity 1808 MW [2]. In low head hydropower schemes cost contribution towards electro-mechanical equipment is higher than the civil works. In earlier studies, correlations for estimation of costs of hydropower schemes were developed based on collected cost data of existing projects [3-5]. An approach was presented for investment analysis of small and medium hydropower projects based on economic and financial analysis [6]. In high and medium head small hydropower schemes, which are mainly run-of-river, the schemes are site specific and installation cost is governed by the cost of civil works. In low head schemes mainly canal based, the machine sizes are relatively larger and the cost is governed by the civil works as well as electro-mechanical equipment. The size of power house and other civil works components are directly affected by the type and size of machines (hydro turbines). Thus there is scope for optimisation in design and selection of techynology for such schemes. Under the present study, an attempt has been made to determine cost of different components of such 


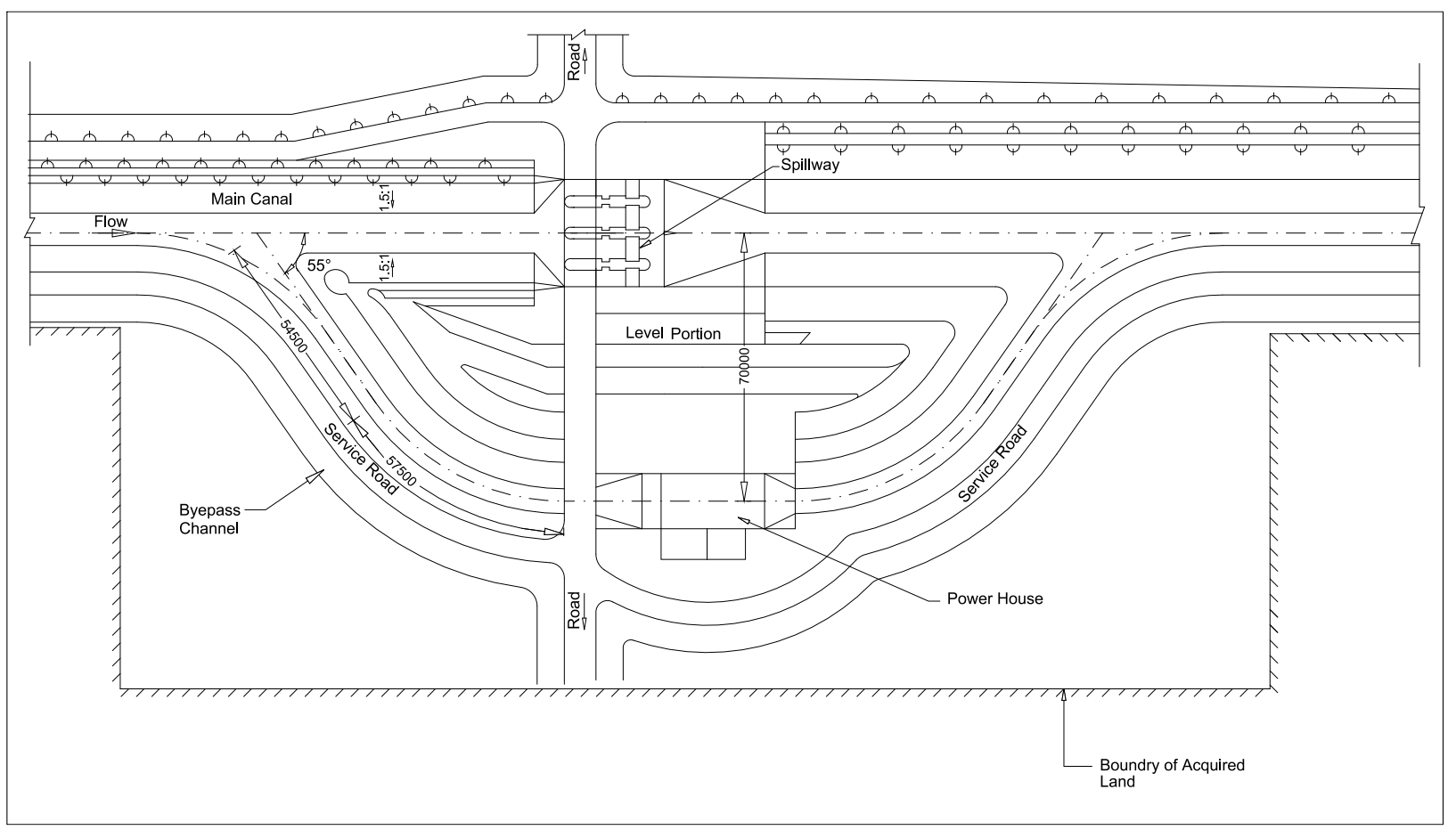

Fig. (1). Typical layout of canal based low head SHP scheme.

schemes with different layouts having different types of turbine and generator. The correlations for the cost are developed and financial analysis is carried out considering installation cost, generation cost and benefit cost ratio at different load factors for selection of optimum layout of canal based SHP schemes.

\section{CANAL BASED LOW HEAD SHP SCHEMES}

In India, small hydropower has been defined based on installed capacity i.e. upto $25 \mathrm{MW}$. SHP schemes are further classified as micro hydro up to $100 \mathrm{~kW}$, mini hydro from $101 \mathrm{~kW}$ to $2000 \mathrm{~kW}$ and small hydro up to $25000 \mathrm{~kW}$ plant capacities with unit size $1000 \mathrm{~kW}$ to $5000 \mathrm{~kW}$ [7]. Small hydropower projects are categorized in two types as; (i) Small hydropower schemes in the hills, where small streams are available. These are mostly of medium/high head utilizing small discharges and known as run of river and dam based schemes. (ii) Small hydropower schemes in the plains and other region of the country which utilize water regulated for other purposes like irrigation/drinking through canals, small dams etc. are usually of low head utilizing large discharges. These schemes are categorized as canal based schemes and dam based schemes. Further, small hydropower schemes are classified based on head as low head from 3 to $20 \mathrm{~m}$, medium head from 20 to $60 \mathrm{~m}$ and high head more than $60 \mathrm{~m}$. These limits are not rigid but are for categorizing the sites [8].

Canal based small hydropower plants are planned close to load centres and provide electricity reliably and cost effectively and avoiding transmission and distributions losses. A typical layout of canal based low head small hydropower scheme is shown in Fig. (1). The main components of civil works in canal based low head schemes are diversion channel, spillway and power house building as described below.

\subsection{Diversion Channel}

The main functions of the diversion channel (or bypass channel) are (i) to divert the required quantity of water towards the power house and pass the balance flow down the main canal and (ii) to instantaneously come into action to pass the water down the canal, when the power house trips. The second function is of great importance as it means not only the prevention of upsurge and consequent danger of overtopping of the canal banks on the upstream, but also maintaining flow continuity in the canal downstream.

\subsection{Spillway}

The spillway arrangement can be made in the main canal or diversion channel as per site conditions to pass the surplus water.

\subsection{Power House Building}

Power house is a simple structure housing the generating units (turbines and generators), auxiliary equipment with sufficient height to accommodate crane operations, and sufficient space for maintenance and control operations. It can be constructed as a steel structure consisting of columns, beams and trusses etc. or it can be reinforced concrete framed structure. The power house may be divided into four distinguished areas such as the main machine hall, erection bay, control bay and other services areas. The main area, housing turbine/generator is the central area around which the service and erection areas are positioned.

The electro-mechanical equipment are divided in following major components.

a) Turbine with governing system 
Table 1. Part Load (Discharge Ratio) Efficiency

\begin{tabular}{|c|c|c|c|c|c|c|c|c|}
\hline \multirow{2}{*}{ S. No. } & \multirow{2}{*}{ Type of Turbines } & \multicolumn{6}{|c|}{ Efficiency at Part Load/Discharge Ratio } & \multirow{2}{*}{ Maximum Efficiency } \\
\cline { 3 - 9 } & & $\mathbf{1 0 0 \%}$ & $\mathbf{9 0 \%}$ & $\mathbf{8 0 \%}$ & $\mathbf{7 0 \%}$ & $\mathbf{6 0 \%}$ & $\mathbf{5 0 \%}$ & 0.82 \\
\hline \hline $\boldsymbol{1 .}$ & Tubular Semi Kaplan & 0.90 & 0.90 & 0.90 & 0.88 & 0.85 & 0.90 \\
\hline 2. & Vertical Semi Kaplan & 0.89 & 0.89 & 0.89 & 0.87 & 0.84 & 0.81 & 0.89 \\
\hline 3. & Bulb Semi Kaplan & 0.91 & 0.91 & 0.91 & 0.89 & 0.86 & 0.83 & 0.91 \\
\hline 4. & Tubular Propeller & 0.89 & 0.88 & 0.85 & 0.80 & 0.75 & 0.70 & 0.89 \\
\hline 5. & Vertical Propeller & 0.88 & 0.87 & 0.84 & 0.79 & 0.74 & 0.69 & 0.88 \\
\hline 6. & Bulb Propeller & 0.90 & 0.89 & 0.86 & 0.81 & 0.76 & 0.71 & 0.90 \\
\hline 7. & Tubular Kaplan & 0.92 & 0.92 & 0.92 & 0.91 & 0.90 & 0.89 & 0.92 \\
\hline 8. & Vertical Kaplan & 0.91 & 0.91 & 0.91 & 0.90 & 0.89 & 0.88 & 0.91 \\
\hline 9. & Bulb Kaplan & 0.93 & 0.93 & 0.93 & 0.92 & 0.91 & 0.90 & 0.93 \\
\hline
\end{tabular}

b) Generator with excitation system, switch gear, control and protection equipment.

c) Electrical and mechanical auxiliary.

d) Transformer and switchyard equipment

Among these components, turbine and generator are considered to be important in terms of spatial requirements and costs.

\subsection{Turbine}

Tubular and bulb turbines are mostly used turbines in the low head SHP schemes having unit capacity upto $5000 \mathrm{~kW}$. In tubular turbine, orientation of shaft can be horizontal or vertical and generators with these turbines are located outside of the water passageway. However in case of bulb turbine, generator is located in water tight enclosure (bulb). These turbines are further classified as propeller, semi Kaplan and Kaplan based on flexibility in movement of runner blades and wicket gates. The turbine with propeller runner has fixed blades and movable wicket gates, turbine with semi Kaplan runner has fixed wicket gates and adjustable runner blades, while turbine with Kaplan runner has adjustable blades and movable wicket gates [9]. These turbines under part load operating conditions have different efficiency. Part load efficiency for different turbines are given in Table $\mathbf{1}$. Generally installation of more than one unit of turbines is recommended at a given site.

\subsection{Generator}

In small hydropower schemes generally two types of generators i.e. induction and synchronous are installed. In case of induction generator, excitation system gets the power from grid and is considered rugged in design, however commercially available induction generators are limited upto a capacity of $3500 \mathrm{~kW}$ [10].

\section{POLICY AND INCENTIVES FOR DEVELOPMENT OF SHP}

In India the importance of renewable energy development was recognized as early as in 1970. At central govern- ment level, Department of Non-Conventional Energy was established in 1982 which was subsequently upgraded to Ministry of Non-conventional Energy Sources and renamed as Ministry of New and Renewable Energy since October 2006. Till 1991, the electricity generation and distribution in India was in government sector only, after that it was opened to private sector also for development. The present share of private sector in hydropower generation is $3.3 \%$ and $12 \%$ in all forms of energy generation. India is a union of states and there is a division of executive and legislative powers between the Indian Union (Central government) and the states. Hydropower is a state subject and interstate rivers are dealt by central government. Hence for hydropower development both the central and state governments are involved.

With the beginning of $21^{\text {st }}$ century, commercialization in the SHP sector took new dimensions. Private entrepreneurs found attractive business opportunities in small hydro. State governments started formulation/ refinement of policies to make hydropower development, entrepreneurs friendly. The procedure of allotment of sites was stream lined and made more transparent. The government of India announced new electricity act in 2003, national electricity policy in 2005 and tariff policy in 2006 to create a conductive atmosphere for investments in the power sector. The electricity act 2003 has specific provisions for the promotion of renewable energy including small hydropower. It has been made mandatory that every state would specify a percentage of electricity to be purchased from renewable. Small hydropower projects are now governed by these policies and tariff is decided by state electricity regulatory commissions as per tariff policy. A package of incentives include customs duty concession, income tax exemption on SHP projects for power generation for 10 years. Some states of India are also giving sales tax and electricity tax exemption on the electricity generated by SHP projects. Sixteen states have framed policies on SHP. Main features of these policies are given below [2]:

- Private sector participation in hydropower including SHP has been permitted.

- Wheeling of power has been permitted. 
Table 2. Subsidy Scheme for New Potential SHP Sites

\begin{tabular}{|c|c|c|c|c|}
\hline Schemes & Areas & $\begin{array}{c}\text { Up to 1 MW } \\
\text { (Rs.) }\end{array}$ & Above 1 MW \& up to 5 MW (Rs.) & Above 5 MW (Rs.) \\
\hline \hline \multirow{2}{*}{$\begin{array}{c}\text { Survey \& investigation } \\
\text { Feasibility report prepara- } \\
\text { tion }\end{array}$} & Plain & 75,000 & $1,00,000$ & $1,50,000$ \\
& Hilly & $1,00,000$ & $2,00,000$ & $3,00,000$ \\
\hline
\end{tabular}

- Power banking is permitted

- Buy back of electricity per unit is generally at the rate of Rs. 2.50, although it varies in different states. Many states provide for annual escalation of rates.

- Third party sale of power is allowed in many states even outside the state.

- States provide other concessions such as lease of land, exemption from electricity duty and entry tax on power generation equipment.

- Some states do not levy any water charges while some levy it as a percentage of electricity tariffs.

- All states have appointed nodal agencies to facilitate participation of developers.

- Some states have prescribed the minimum quantum of power produced from renewable sources that the state distribution licensee must purchase.

The Ministry of New and Renewable Energy gives the following subsidies on SHP projects [11].

1. For special category states (North-Eastern region, Sikkim, Jammu \& Kashmir, Himachal Pradesh and Uttarakhand) the amount of subsidy is Rs. $22.5 \mathrm{x}$ $\mathrm{CMW}^{\wedge} 0.646$ millions. For other states, the amount of subsidy is Rs. $15 \times \mathrm{CMW}^{\wedge} 0.646$ millions. CMW means capacity of SHP station in MW.

2. Subsidy for renovation and modernization of old SHP projects and for completion of languishing SHP projects is limited to $50 \%$ of the subsidy amount applicable for new SHP projects. However this support is only for the government sector.

3. Subsidy for identification of new potential sites and preparation of perspective plans by state agencies are shown in Table $\mathbf{2}$.

\section{COST ANALYSIS FOR OPTIMUM INSTALLA- TION}

In the present study, an analysis has been carried out for development of correlations for the cost of various components of canal based low head small hydropower schemes having two units in the head range 3 to $20 \mathrm{~m}$ and unit size 1000 to $5000 \mathrm{~kW}$. The cost has been determined for various cases of layouts having different head and capacity based on actual quantities of various items with prevailing rates. The correlation for cost as a function of head and capacity were developed by regression analysis for the layouts having different type of turbines and generators. These correlations were developed based on the methodology developed by the authors in earlier investigation [12].

For all the cases considered, runner diameter (D) has been worked out by using following equation [13].

$$
D=\frac{84.6 \theta_{3}(H)^{1 / 2}}{N}
$$

The parameter (velocity ratio at discharge diameter of runner) $\theta_{3}$ and specific speed $\mathrm{N}_{\mathrm{s}}$ were determined by the following expressions.

$$
\begin{aligned}
& \theta_{3}=0.0223\left(N_{s}\right)^{2 / 3} \\
& N_{s}=\frac{N \sqrt{P} \times 1.358}{H^{5 / 4}}
\end{aligned}
$$

Sizes of other components and quantities of civil works have been determined based on the runner diameter of the turbine which is considered one of the main deciding parameter for sizing of SHP components.

\subsection{Civil Works}

Fig. (1) shows layout of a typical low head small hydropower scheme considered under the present investigation. Costs of various components under civil works viz. diversion channel, spillway and power house building have been determined for different cases based on prevailing rates of civil works for the year 2007. The cost has been worked out based on actual quantities of different items such as earthwork in excavation/filling, concreting, reinforcement steel, fabricated steel structure (gates, trash racks, roofing trusses, railings etc.) and other miscellaneous items such as doors, widows, floor finishing, plastering, sanitary and water supply works, drainage, fencing paintings etc.

Based on the determined values of costs for different components of civil works, correlations have been developed by regression analysis approach considering head and capacity as cost sensitive parameters. All costs are taken in Indian Rupees (Rs).

Correlations for cost per $\mathrm{kW}$ of different components under civil works, diversion channel $\left(C_{1}\right)$, spillway $\left(C_{2}\right)$ and power house building $\left(\mathrm{C}_{3}\right)$ have been developed and are given below;

$$
\begin{array}{ll}
\mathrm{C}_{1}=a_{1} P^{x_{1}} & H^{y_{1}} \\
\mathrm{C}_{2}=a_{2} P^{x_{2}} & H^{y_{2}} \\
\mathrm{C}_{3}=a_{3} P^{x_{3}} \quad H^{y_{3}}
\end{array}
$$


Table 3. Coefficient for Cost Correlations of Civil Works

\begin{tabular}{|c|c|c|c|c|c|}
\hline \multirow{3}{*}{ S. No. } & \multirow{3}{*}{ Type of Turbine } & \multirow{3}{*}{ Type of Generator } & \multicolumn{3}{|c|}{ Coefficient for Cost Correlations } \\
\hline & & & \multicolumn{3}{|c|}{$\begin{array}{c}\text { Power House } \\
\left(c_{3}\right)\end{array}$} \\
\hline & & & $\mathbf{a}_{3}$ & $\mathbf{x}_{3}$ & $\mathbf{y}_{3}$ \\
\hline 1. & Tubular Semi Kaplan & Synchronous & 105555 & -0.2380 & -0.0602 \\
\hline 3. & Vertical Semi Kaplan & Synchronous & 94594 & -0.2377 & -0.0622 \\
\hline 4. & Vertical Semi Kaplan & Induction & 94594 & -0.2377 & -0.0622 \\
\hline 5. & Bulb Semi Kaplan & Synchronous & 85805 & -0.2371 & -0.0599 \\
\hline 6. & Bulb Semi Kaplan & Induction & 85805 & -0.2371 & -0.0599 \\
\hline 10. & Vertical Propeller & Induction & 93133 & -0.2382 & -0.0624 \\
\hline 11. & Bulb Propeller & Synchronous & 82122 & -0.2384 & -0.0604 \\
\hline 12. & Bulb Propeller & Induction & 82122 & -0.2384 & -0.0604 \\
\hline 13. & Tubular Kaplan & Synchronous & 111756 & -0.2389 & -0.0605 \\
\hline 14. & Tubular Kaplan & Induction & 111756 & -0.2389 & -0.0605 \\
\hline 15. & Vertical Kaplan & Synchronous & 100998 & -0.2387 & -0.0607 \\
\hline 16. & Vertical Kaplan & Induction & 100998 & -0.2387 & -0.0607 \\
\hline
\end{tabular}

Cost per $\mathrm{kW}$ of civil works worked out for each case is represented by the expression given below.

The values of coefficients in Eq.4 and Eq. 5 have been determined and are given below;

$$
\begin{aligned}
& \mathrm{a}_{1}=9904, \mathrm{x}_{1}=-0.2295, \mathrm{y}_{1}=-0.0623 \\
& \mathrm{a}_{2}=36778, \mathrm{x}_{2}=-0.2306, \mathrm{y}_{2}=-0.0644
\end{aligned}
$$

The coefficients in the correlations for diversion channel and spillway are found to be same, however these are different for power house building for different types of hydro turbines and values of these coefficients are given in Table $\mathbf{3}$.

$\mathrm{C}_{\mathrm{c}}=\mathrm{C}_{1}+\mathrm{C}_{2}+\mathrm{C}_{3}$

\subsection{Electro-Mechanical Equipment}

Cost of various components of electro-mechanical equipment have been worked out as per prevailing rates based on runner diameter and capacity of the plant for different types of turbines and generators. Based on the cost determined for different cases, correlations have been developed by regression analysis considering head and capacity as cost sensitive parameters. A similar methodology as used for development of the correlations for cost of civil works, has been used to develop the correlations for cost of different components of electro-mechanical equipment. The devel- oped correlations for the cost of turbines with governing system, generator with excitation system, electrical and mechanical auxiliary and transformer \& switchyard equipment are represented as follows;

$$
\begin{array}{ll}
\mathrm{C}_{4}=a_{4} P^{x_{4}} & H^{y_{4}} \\
\mathrm{C}_{5}=a_{5} P^{x_{5}} & H^{y_{5}} \\
\mathrm{C}_{6}=a_{6} P^{x_{6}} & H^{y_{6}} \\
\mathrm{C}_{7}=a_{7} P^{x_{7}} H^{y_{7}}
\end{array}
$$

Values of coefficients have been found same in correlation for transformer and switchyard. For all the cases considered, the values of coefficient determined for this component are as given below.

$$
\mathrm{a}_{7}=18739, \mathrm{x}_{7}=-0.1803, \mathrm{y}_{7}=-0.2075
$$

However, values of coefficients for other components were found to be different which are given in Table 4.

Cost per $\mathrm{kW}$ of electro-mechanical equipment has been worked out by using the expression given below.

$\mathrm{C}_{\mathrm{e} \& \mathrm{~m}}=\mathrm{C}_{4}+\mathrm{C}_{5}+\mathrm{C}_{6}+\mathrm{C}_{7}$ 
Table 4. Coefficients for Cost Correlations of Electro-Mechanical Equipment

\begin{tabular}{|c|c|c|c|c|c|c|c|c|c|c|c|}
\hline \multirow{3}{*}{$\begin{array}{l}\text { S. } \\
\text { No }\end{array}$} & \multirow[t]{3}{*}{ Type of Turbines } & \multirow{3}{*}{$\begin{array}{l}\text { Type of } \\
\text { Generator }\end{array}$} & \multicolumn{9}{|c|}{ Coefficients for Cost Correlations } \\
\hline & & & \multicolumn{3}{|c|}{$\begin{array}{l}\text { Turbine with Governing System } \\
\qquad\left(c_{4}\right)\end{array}$} & \multicolumn{3}{|c|}{$\begin{array}{c}\text { Generator with Excitation System } \\
\left(\mathbf{c}_{5}\right)\end{array}$} & \multicolumn{3}{|c|}{$\begin{array}{c}\text { Electrical and Mechanical } \\
\text { Auxiliary }\left(c_{6}\right)\end{array}$} \\
\hline & & & $\mathbf{a}_{4}$ & $\mathbf{x}_{4}$ & $\mathbf{y}_{4}$ & $\mathbf{a}_{5}$ & $\mathbf{x}_{5}$ & $\mathbf{y}_{5}$ & $\mathbf{a}_{6}$ & $\mathbf{x}_{6}$ & $\mathrm{y}_{6}$ \\
\hline 1. & Tubular Semi Kaplan & Synchronous & 63346 & -0.1913 & -0.2171 & 78661 & -0.1855 & -0.2083 & 40860 & -0.1892 & -0.2118 \\
\hline 2. & Tubular Semi Kaplan & Induction & 63346 & -0.1913 & -0.2171 & 66268 & -0.1882 & -0.2070 & 35930 & -0.1831 & -0.2098 \\
\hline 3. & Vertical Semi Kaplan & Synchronous & 62902 & -0.1835 & -0.2092 & 83091 & -0.1827 & -0.2097 & 42332 & -0.1859 & -0.2084 \\
\hline 4. & Vertical Semi Kaplan & Induction & 62902 & -0.1835 & -0.2092 & 70299 & -0.1826 & -0.2125 & 37171 & -0.1848 & -0.2094 \\
\hline 5. & Bulb Semi Kaplan & Synchronous & 67015 & -0.1824 & -0.2092 & 91696 & -0.1893 & -0.2137 & 44044 & -0.1858 & -0.2141 \\
\hline 6. & Bulb Semi Kaplan & Induction & 67015 & -0.1824 & -0.2092 & 78258 & -0.1833 & -0.2091 & 39223 & -0.1800 & -0.1986 \\
\hline 7. & Tubular Propellor & Synchronous & 61153 & -0.1961 & -0.2111 & 78661 & -0.1855 & -0.2083 & 38328 & -0.1902 & -0.2134 \\
\hline 8. & Tubular Propellor & Induction & 61153 & -0.1961 & -0.2111 & 66268 & -0.1882 & -0.2070 & 34124 & -0.1897 & -0.2196 \\
\hline 9. & Vertical Propellor & Synchronous & 59264 & -0.1817 & -0.2106 & 83091 & -0.1827 & -0.2097 & 39665 & -0.1863 & -0.2082 \\
\hline 10. & Vertical Propellor & Induction & 59264 & -0.1817 & -0.2106 & 70299 & -0.1826 & -0.2125 & 34852 & -0.1865 & -0.2120 \\
\hline 11. & Bulb Propellor & Synchronous & 64017 & -0.1850 & -0.2031 & 91696 & -0.1893 & -0.2137 & 42641 & -0.1929 & -0.2048 \\
\hline 12. & Bulb Propellor & Induction & 64017 & -0.1850 & -0.2031 & 78258 & -0.1833 & -0.2091 & 37513 & -0.1831 & -0.2119 \\
\hline 13. & Tubular Kaplan & Synchronous & 70170 & -0.1853 & -0.2053 & 81881 & -0.1858 & -0.2095 & 41982 & -0.1870 & -0.2099 \\
\hline 14. & Tubular Kaplan & Induction & 70170 & -0.1853 & -0.2053 & 72121 & -0.1868 & -0.2082 & 37168 & -0.1840 & -0.2156 \\
\hline 15. & Vertical Kaplan & Synchronous & 73624 & -0.1872 & -0.2105 & 85377 & -0.1816 & -0.2082 & 44729 & -0.1924 & -0.2166 \\
\hline 16. & Vertical Kaplan & Induction & 73624 & -0.1872 & -0.2105 & 77693 & -0.1840 & -0.2096 & 39199 & -0.1805 & -0.2072 \\
\hline 17. & Bulb Kaplan & Synchronous & 75048 & -0.1873 & -0.2086 & 99401 & -0.1886 & -0.2090 & 45326 & -0.1912 & -0.2072 \\
\hline 18. & Bulb Kaplan & Induction & 75048 & -0.1873 & -0.2086 & 85417 & -0.1880 & -0.2096 & 40096 & -0.1847 & -0.2156 \\
\hline
\end{tabular}

\subsection{Total Cost}

The cost of civil works, cost of electro- mechanical equipment, cost of other miscellaneous items and other indirect costs constitute the total cost. Establishment related cost including designs, audit \& account, indirect charges, tools and plants, communication expenses, preliminary expenses on report preparation, survey and investigations and cost of land were considered under miscellaneous and indirect costs. $13 \%$ of the cost of civil works and electro- mechanical equipment has been taken on account of these costs [12].

Total cost per $\mathrm{kW}$ has been worked out by using following expression.

$$
\mathrm{C}=1.13\left(\mathrm{C}_{\mathrm{c}}+\mathrm{C}_{\mathrm{e} \& \mathrm{~m}}\right)
$$

\section{ANALYSIS FOR OPTIMUM INSTALLATION}

Financial analysis has been carried out for different layouts where power house is in the diversion channel and spillway in the main canal. Two units of generating equipment were considered and different type of turbine and generators were taken. The soil condition was considered as ordinary soil. The financial analysis for different schemes has been made based on the followings;

(a) Installation cost (b) Generation cost

(c) Benefit-cost ratio

\subsection{Generation Cost}

Generation cost has been worked out in Rs/kWh at different load factors for different type of turbines and generators based on annual cost and annual energy generation. Annual cost for generation of electric energy included operation and maintenance (O\&M), insurance cost, depreciation of civil works \& equipment, interest on the capital invested and replacement cost. Annual cost has been taken as $16 \%$ of the project cost. Details of these costs are discussed below.

\subsubsection{O\&M Cost}

O\&M cost include salary/wages of the personnel, labour charges, insurance, spares and consumables to keep the power plant in operating condition. These costs have been taken as $1.5 \%$ of project cost [14].

\subsubsection{Depreciation}

The civil works and equipment get depreciated over the life of the project. An annual rate of depreciation was taken based on life of the project. The life of hydropower plant considered 35 years, accordingly annual depreciation rate has been taken as $3.4 \%$ in the analysis [14]. 


\subsubsection{Interest}

10 to $12 \%$ interest rates being charged by the leading financial institutions for small hydropower sector. Accordingly an average rate of $11 \%$ has been taken for the analysis.

\subsubsection{Energy Generation}

Energy generation for all the cases was calculated by using the following expression;

$\mathrm{E}=\mathrm{P} \times 8760 \times \eta_{\mathrm{T}} \times \eta_{\mathrm{g}} \times \mathrm{P}_{\mathrm{L}}$

\subsection{Benefit Cost Ratio}

The Benefit-Cost (B-C) analysis has been used for evaluating the economic viability of the project. The B-C ratio is the ratio of the present value of future cash flows (benefits) to the present value of the original and subsequent cash out flows. Basically two types of benefits i.e. tangible and intangible benefits are available for small hydropower projects. The tangible benefit is the sale of electrical energy generated. In India different states have different rates for electricity varying from Rs. 1.75 to Rs. 3.00 per $\mathrm{kWh}$. An average value of Rs. 2.50 per $\mathrm{kWh}$ which is also prevailing rate in many states has been taken for the analysis. Accordingly, benefits cost ratio is worked out as follows;

Benefits cost ratio $(\mathrm{B}-\mathrm{C}$ ratio $)=\frac{\text { Present value of benefits }}{\text { Present value of expenditure }}$

The intangible benefits are the positive environmental effects, recreation opportunities due to development in water bodies, social upliftment due to development activities and infrastructure development. The intangible benefits are qualitative in nature hence not considered in the analysis.

\subsubsection{Present Value of Benefits}

In order to get consistent values for both benefit and cost, the present value criterion has been adopted. Under the procedure, the present value at the time of first expenditure of the future stream of benefits was calculated by fixing the discount rate. The present value (PV) of the scheme has been evaluated by using the expression given below [15]:

$\mathrm{PV}=\sum_{i=1}^{n}\left[\frac{C F_{i}}{(1+d)^{i}}\right]$

The life of the plant has been taken as 35 years and it was considered that after 25 years major replacement of equipment and renovation of works may be required which has more annual cost due to this and energy will not be available during renovation of the unit and associated works. Thus present value of benefits has been worked out for 25 years after the plant put in to operation.

\subsubsection{Present Value of Expenditure}

The construction period has been considered as 2 years as it is found that such plants were installed even in less than 2 years in the recent past. The installation cost was divided as $77 \%$ in first year and $23 \%$ in second year [6]. Present value of expenditure has been worked out by taking installa- tion cost in 2 years and then annual cost in subsequent 25 years in the same way as present value of benefits was calculated.

\subsubsection{Discount Rate}

Discount rate signifies the time value of money and is the cost of the capital investment. Discount rate is also the opportunity cost of the capital. The source of capital is the equity and the loan. The equity and debt (loan) ratio has been taken as 30:70 based on the guidelines for financing by leading financial institutions. The discount rate was taken $11 \%$ as prevailing.

\subsubsection{Inflation}

The inflation based on consumer price index for the years 1995 to 2007 varies from $3.3 \%$ to $8 \%$. The average inflation during this period comes out to be around $5 \%$, which has been taken as inflation on benefits from sale of electrical energy and the O\&M cost [12].

\section{RESULTS AND DISCUSSIONS}

In the present study the power scenario and government policy for SHP development with respect to India has been presented. There is still short fall of power which is to be augmented through renewable sources of energy. Small hydropower is the promising source of renewable energy and has good potential in India. The components of low head SHP scheme are discussed and analysis of cost carried out.

Fig. (2) presents the project installation cost and generation cost at $100 \%$ load factor at $3 \mathrm{~m}$ head and capacity of $2000 \mathrm{~kW}$. The cost has been worked out based on the correlations developed for costs for various layouts having different type of turbines and generators. The correlations for cost of civil works components and electro- mechanical equipment were developed by regression analysis. It is seen that, in case of layout, where power house is in the diversion channel and spillway in the main channel, tubular turbine with propeller runner coupled with induction generator found to be the optimum layout as it has minimum installation cost i.e. Rs.64,500 per $\mathrm{kW}$ as well as generation cost Rs.1.41 per kWh at $100 \%$ load factor. For a particular layout, installation cost is the same but generation cost varies at different load factors due to change in efficiency.

Fig. (3) and (4) present the generation cost and benefits cost ratio for layouts based on different electro-mechanical equipment at various load factors. It is seen that, bulb turbine with Kaplan runner coupled with induction generator is the optimum layout at low load factor i.e. $50 \%$, as it corresponds to the minimum generation cost Rs.3.41 per kWh and maximum benefits cost ratio as 0.68 . These figures are relative and it is obvious that generation cost is higher and benefit cost ratio low at low load factors. At load factors 60 to $80 \%$, tubular turbine having semi Kaplan runner results in the minimum generation cost and maximum benefit and can be considered as optimum layout.

Layout of the SHP scheme having tubular turbine with propeller runner found to be optimum at higher load factors i.e. 90 to $100 \%$ as this layout has minimum generation cost and maximum benefit cost ratio. 


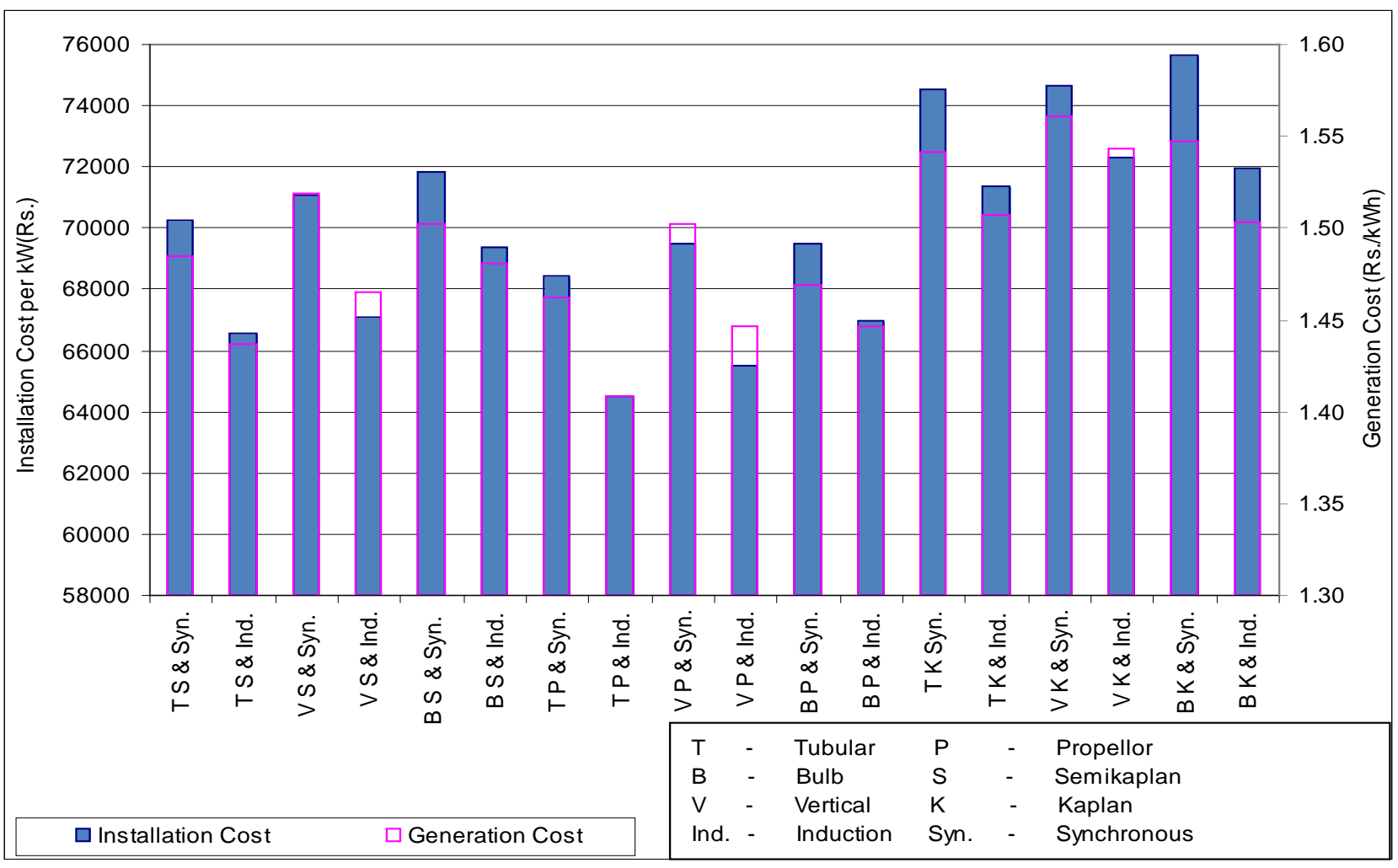

Fig. (2). Layouts at $3 \mathrm{~m}$ head and $2000 \mathrm{~kW}$ at $100 \%$ load factor.

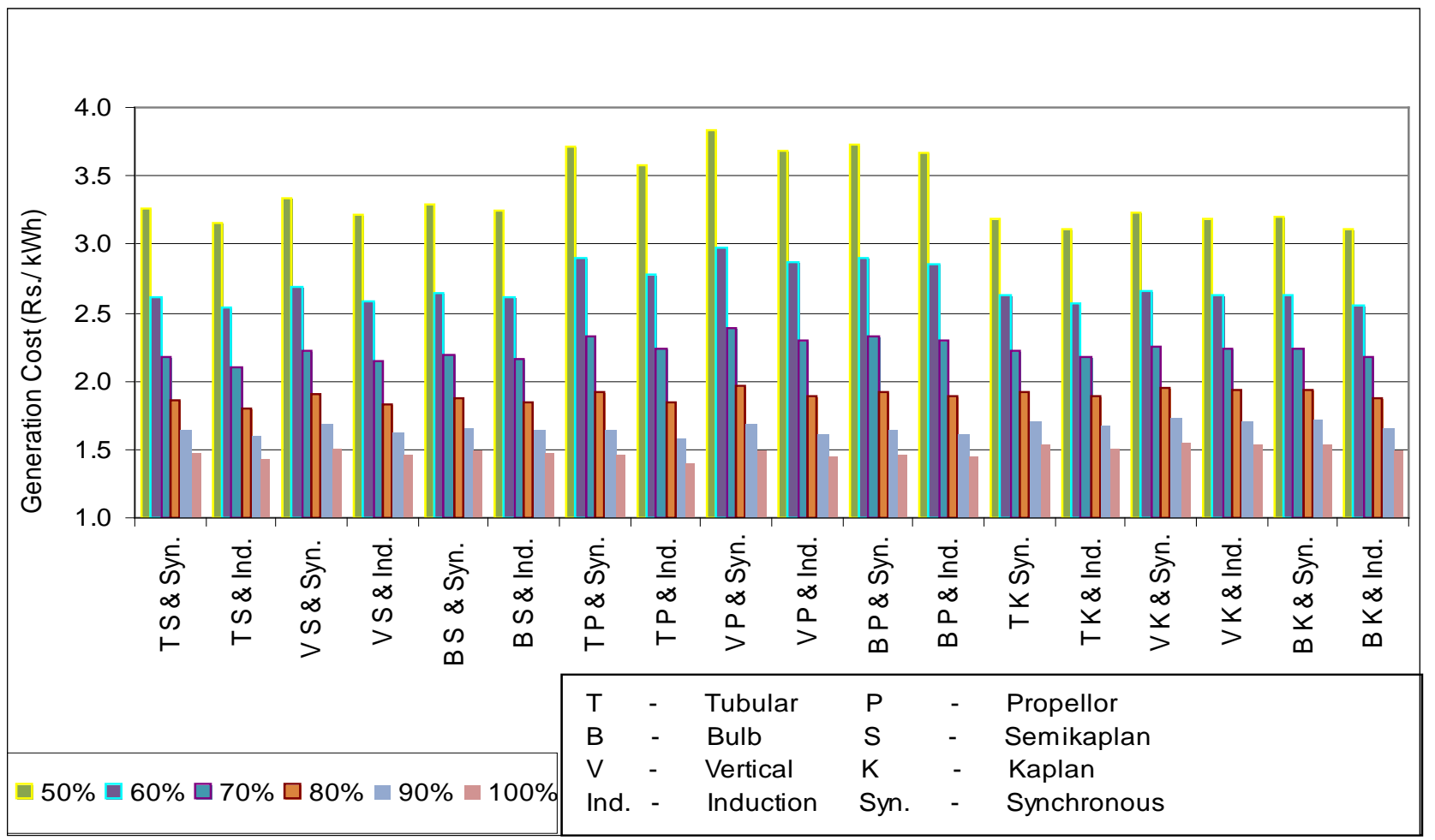

Fig. (3). Generation cost at $3 \mathrm{~m}$ head and $2000 \mathrm{~kW}$ at different load factors.

\section{CONCLUSIONS}

The correlations for cost of various components of canal based SHP schemes for different layouts having different types of turbines and generators were developed by regression analysis based on actual quantities of various items having prevailing rates. Based on developed correlations, installation cost of the scheme has been worked out. These corre- 


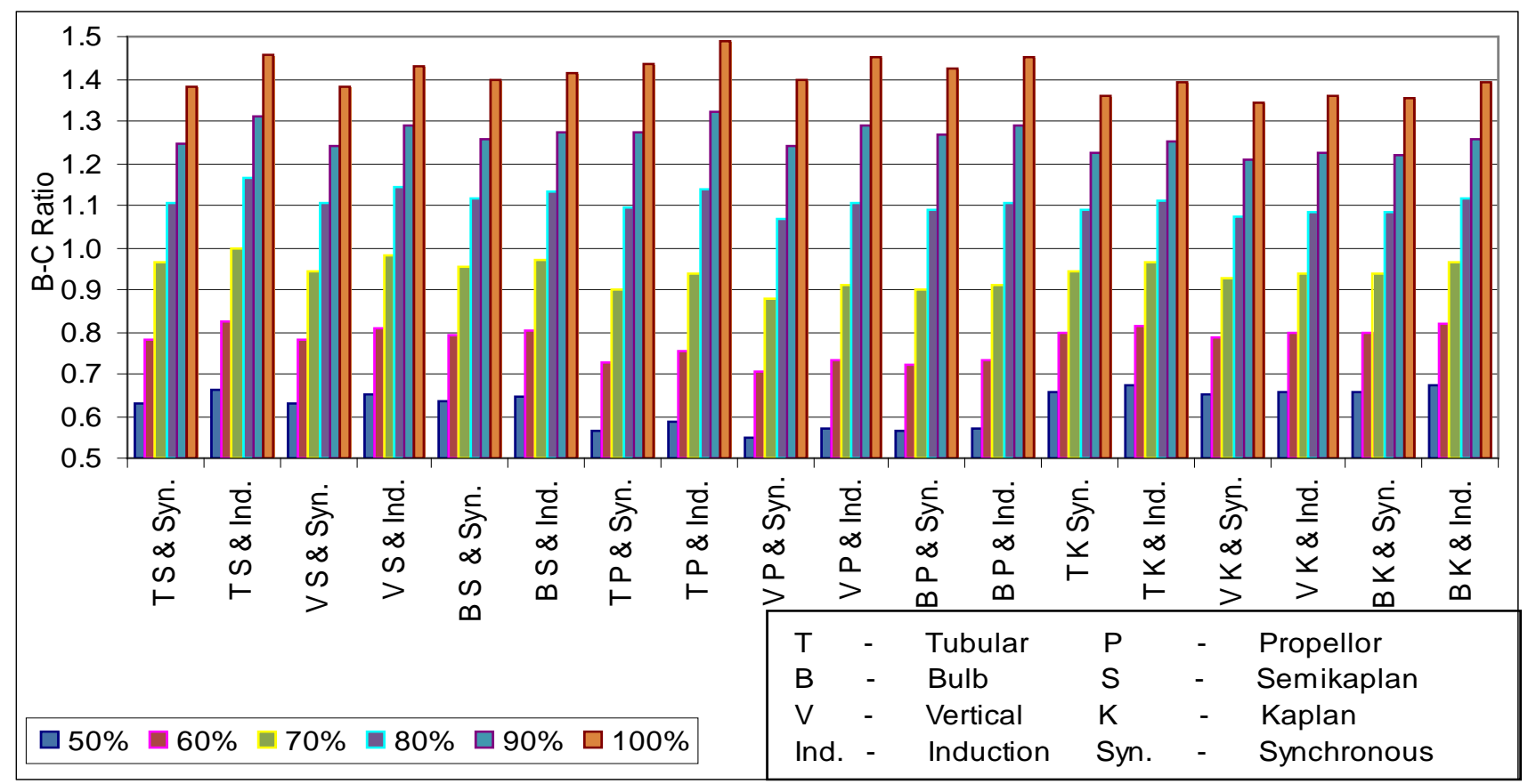

Fig. (4). B-C ratio at $3 \mathrm{~m}$ head and $2000 \mathrm{~kW}$ at different load factors.

lations are useful in knowing the installation cost of the scheme to take the investment decision. Generation cost and benefit cost ratio were determined at different load factors. It is found that the layout having Bulb turbine with Kaplan runner is found as optimum at low load factor (50\%) while the layout of tubular turbine with propeller runner and induction generator has been found to be optimum at high load factors for 90 to $100 \%$.

Further, tubular turbine with semi Kaplan runner is found to be optimum layout at load factors for 60 to $80 \%$ having minimum generation cost and maximum benefit cost ratio.

\section{NOMENCLATURE}

$\theta_{3}=$ Velocity ratio at discharge diameter of runner

$\eta_{\mathrm{g}} \quad=$ Efficiency of generator

$\eta_{\mathrm{T}} \quad=$ Efficiency of turbine

$\mathrm{a}_{1}-\mathrm{a}_{7}=$ Coefficients

$\mathrm{B}-\mathrm{C}=$ Benefit-cost

$\mathrm{C}=$ Total cost per $\mathrm{kW}$ in Rs.

$\mathrm{C}_{1}=$ Cost per $\mathrm{kW}$ of diversion channel

$\mathrm{C}_{2} \quad=$ Cost per $\mathrm{kW}$ of spillway

$\mathrm{C}_{3} \quad=$ Cost per $\mathrm{kW}$ of power house building

$\mathrm{C}_{4}=$ Cost per $\mathrm{kW}$ of turbines with governing system

$\mathrm{C}_{5} \quad=$ Cost per $\mathrm{kW}$ of generator with excitation system

$\mathrm{C}_{6}=$ Cost per $\mathrm{kW}$ of electrical and mechanical auxiliary

$\mathrm{C}_{7}=$ Cost per $\mathrm{kW}$ of transformer $\&$ switchyard equipment

$\mathrm{C}_{\mathrm{c}} \quad=$ Cost per $\mathrm{kW}$ of civil works

$\mathrm{C}_{\mathrm{e} \& \mathrm{~m}}=$ Cost per $\mathrm{kW}$ of electro-mechanical equipment

CEA = Central Electricity Authority, Government of India
$\mathrm{CFi}=$ Cash flow in ith year starting with initial investment

$\mathrm{d}=$ Discount rate

$\mathrm{D}=$ Runner diameter in meter

$\mathrm{E} \quad=$ Annual energy generation in $\mathrm{kWh}$

$\mathrm{GW}=$ Gigawatt

$\mathrm{H} \quad=$ Rated net head in meter

$\mathrm{kW}=$ Kilowatt

$\mathrm{kWh}=$ =Kilowatt hour

$\mathrm{m}=$ Meter

MW = Megawatt

$\mathrm{n}=$ Last year of cash flow

$\mathrm{N} \quad=$ Rotational speed of turbine in revolution per minute

$\mathrm{N}_{\mathrm{s}} \quad=$ Specific speed

$\mathrm{O} \& \mathrm{M}=$ Operation and maintenance

$\mathrm{P} \quad=$ Rated output power in $\mathrm{kW}$

$\mathrm{P}_{\mathrm{L}}=$ Load factor

$\mathrm{PV}=$ Present value

Rs = Indian rupees

$\mathrm{Rs} / \mathrm{kWh}=$ Rupees per kilowatt hour

SHP = Small hydropower

$\mathrm{TWh}=$ Terawatt hour

$\mathrm{x}_{1}-\mathrm{X}_{7}=$ Coefficients

$\mathrm{y}_{1}-\mathrm{y}_{7}=$ Coefficients 


\section{REFERENCES}

[1] World Atlas and Industry Guide. Int. J. Hydropower Dams, 2007.

[2] Sectoral Report. Small Hydropower Development in India. Alternate Hydro Energy Centre, Indian Institute of Technology, Roorkee, 2007.

[3] Gordon, J.L. Hydropower cost estimates. J. Water Power Dam Construction, 1983, 30-37.

[4] Gordon, J.L.; Noel, R.C.R. The economic limits of small and low head hydro. J. Water Power Dam Construct., 1986, 38(4), 23-26.

[5] Whittington, H.W.; Wallace, A.R.; Henderson, D.S. An Economic Analysis of Capital Costs in Micro-Hydro, Proc., Third International Conference on Small Hydro, International Water Power \& Dam Construction; Cancun: Mexico, 1988, pp.182-197.

[6] Forouzbakhsh, F.; Hosseini, S.M.H.; Vakilian, M. An approach to the investment analysis of small and medium hydro-power plants. Energ. Policy, 2007, 35, 1013-1024.

[7] CEA. Guidelines for Development of Small Hydro Electric Scheme; Govt. of India: New Delhi, 1982.
[8] Emill M. Water Power Development: Low Head Power Plants; Hungarian Academy of Science; Budapest, 1987.

[9] Brown, J.G. Hydro Electric Engineering Practice; CBS Publisher: New Delhi, India, 1984, Vol. I, II and III.

[10] Study on Design and Development of Model SHP Based Self Sustained Projects, Alternate Hydro Energy Centre, Indian Institute of Technology, Roorkee, India, 2002.

[11] Annual Report. Ministry of New and Renewable Energy; Government of India: New Delhi, 2008.

[12] Singal, S.K.; Saini, R.P. Analytical Approach for Development of Correlations for cost of canal based SHP schemes. Renewable Energ. Int. J., 2008, 33, 2549-2558.

[13] IS: 12800 (Part 3), Guidelines for the Selection of Hydraulic Turbine, Preliminary Dimensioning and Layout of Surface HydroElectric Power House (Small, Mini and Micro Hydro-Electric Power House); Bureau of Indian Standards: India, 1991.

[14] India's Electricity Sector - Widening Scope for Private Participation; Ministry of Power; Govt. of India, 1998

[15] Raghuvanshi, C.S. Management and Organisation of Irrigation System; Atlantic Publishers and Distributors: New Delhi, 1995.

Received: September 05, 2008

Revised: October 30, 2008

Accepted: November 04, 2008

(C) Singal et al.; Licensee Bentham Open.

This is an open access article licensed under the terms of the Creative Commons Attribution Non-Commercial License (http://creativecommons.org/licenses/by-nc/3.0/) which permits unrestricted, non-commercial use, distribution and reproduction in any medium, provided the work is properly cited. 